\title{
Validation of Factors Affecting the Outcome of Cardiopulmonary Arrest in a Large, Urban, Academic Medical Center
}

\author{
Dafna Koldobskiy, ${ }^{1}$ Soleyah Groves, ${ }^{2}$ Steven M. Scharf, ${ }^{1}$ and Mark J. Cowan ${ }^{1}$ \\ ${ }^{1}$ Division of Pulmonary and Critical Care Medicine, Department of Medicine, University of Maryland School of Medicine, \\ 10 North Greene Street, Room 3D122D, Baltimore, MD 21201, USA \\ ${ }^{2}$ INOVA Fairfax Hospital, 3300 Gallows Road, Falls Church, VA 22042, USA
}

Correspondence should be addressed to Mark J. Cowan; mark.cowan@verizon.net

Received 22 June 2013; Revised 28 September 2013; Accepted 2 October 2013; Published 27 January 2014

Academic Editor: Ricardo Rivera-Fernández

Copyright (C) 2014 Dafna Koldobskiy et al. This is an open access article distributed under the Creative Commons Attribution License, which permits unrestricted use, distribution, and reproduction in any medium, provided the original work is properly cited.

\begin{abstract}
Background. Recent studies of risks in cardiopulmonary arrest (CPA) have been performed using large databases from a broad mix of hospital settings. However, these risks might be different in a large, urban, academic medical center. We attempted to validate factors influencing outcomes from CPA at the University of Maryland Medical Center (UMMC). Methods. Retrospective chart review of all adult patients who underwent CPA between 2000 and 2005 at UMMC. Risk factors and outcomes were analyzed with appropriate statistical analysis and compared with published results. Results. 729 episodes of CPA were examined during the study period. Surgical patients had better survival than medical or cardiac patients. Intensive care unit' (ICU) patients had poor survival, but there was no difference on monitored or unmonitored floors. Respiratory etiologies survived better than cardiac etiologies. CPR duration and obesity were negatively correlated with outcome, while neurologic disease, trauma, and electrolyte imbalances improved survival. Age, gender, race, presence of a witness, presence of a monitor, comorbidities, or time of day of CPA did not influence survival, although age was associated with differences in comorbidities. Conclusions. UMMC risk factors for CPA survival differed from those in more broad-based studies. Care should be used when applying the results of database studies to specific medical institutions.
\end{abstract}

\section{Introduction}

Since the introduction of closed chest compressions in 1960 [1], cardiopulmonary resuscitation has become the standard intervention in CPA. The ensuing five decades have seen many advances in resuscitation techniques, including the development of Advanced Cardiac Life Support (ACLS) procedures and comprehensive postarrest care [2]. However, the survival-to-discharge rates of $15-20 \%$ are little changed, and survival with good quality of life is rare [3-13].

Given the low success rate and high cost of in-hospital ACLS, an accurate understanding of predictors of survival from CPA could improve decision making for patients, families, healthcare providers, and healthcare payers when considering the appropriate application of resuscitation efforts. Factors previously shown to predict poor CPA outcomes, although with variable strength, consistency, and patient populations [14], include: CPA during off-hours [13, 15-17], longer duration of CPR [18], delayed initiation of CPR/ defibrillation [17-19], comorbidities [6, 9, 12, 18, 20-25], unwitnessed (versus witnessed) arrest $[9,13,23]$, primary cardiac (versus primary respiratory) arrest $[9,13,25]$, pulseless electrical activity (PEA) or asystole (versus ventricular tachycardia (VT) or ventricular fibrillation (VF)) $[9,13,16,20$, $25,26]$, African-American race [27], increased age [9, 16, 18, $20,23,24,28-30]$, and decreased BMI [25, 31]. There are some data to suggest that hospital bed type may influence outcomes $[9,12]$.

There has been increased use of the National Registry of Cardiopulmonary Resuscitation (NRCPR) to report outcomes and assess risk factors from a far larger and more diverse patient population that can be done in smaller studies 
$[15,27,32-34]$. We were interested in determining whether factors influencing CPA outcomes were similar in our large urban academic medical center, which features experienced intensivists managing patients during and immediately after arrest. We present a retrospective review of all resuscitation attempts at the UMMC from 2000 to 2005, examining patient demographics, arrest characteristics, comorbidities, unit and service type, and witnessed status on survival. We hypothesized that there would be important differences in outcomes and risk factors from our institution, with its different patient populations and CPA/post-CPA management, from those in the broad-based medical literature. Any significant differences could be critically important in decision making regarding resuscitation attempts at institutions whose patient population differs from those in the aggregate NRCPR database.

\section{Methods}

This study was approved by the UMMC IRB as H-0023774.

2.1. Study Population. All patients over 18 years of age who underwent CPA between the years 2000 and 2005 in any location in the UMMC, including the emergency room, unmonitored floor units, telemetry units, ICUs, the dialysis unit, and the radiology suite, were included in the study. Patients were excluded if their arrest occurred while being in transit to the hospital or prior to arrival to the emergency room.

2.2. Study Design. CPA was defined as activation of a "Code Blue," with loss of a palpable pulse or respiratory arrest. At the UMMC, a tertiary care university hospital that has 669 floor beds and 265 intensive care beds, nursing fills out a standardized arrest form at every "Code Blue." These forms are saved and abstracted into a Microsoft Excel database by the Anesthesia Department and includes documentation of time and location of CPA, treatment given, cardiac versus respiratory etiology, length of resuscitative efforts, whether the CPA was witnessed or not, and outcome. Cardiopulmonary resuscitation was performed according to the American Heart Association Guidelines [35] per hospital policy.

2.3. Variables. Return of spontaneous circulation (ROSC) was defined as organized electrical activity on a monitor accompanied by a palpable pulse. Identified patients underwent chart review to obtain demographic data, hospital diagnoses, comorbid medical conditions, admission service, and discharge status. We defined 3 levels of inpatient bed types: "unmonitored," representing a typical floor hospital bed, "monitored," with continuous cardiac telemetry, and "intensive care," describing medical, surgical, or cardiac beds with ICU level nursing care and monitoring. "Witnessed arrests" were defined as the presence of an identifiable person (typically nursing or nursing assistants) witnessing the onset of CPA. Demographic data collected included age, sex, and race. Admission services were medicine, surgery, and cardiology. Etiology included primary respiratory or primary cardiac as documented on the arrest form. Major comorbidities were obtained from discharge ICD-9 codes (neurologic disease, alcoholism, cardiovascular disease, respiratory disease, renal disease, endocrinopathy, gastrointestinal disease, diabetes, hypertension, trauma, cancer, infectious disease, electrolyte abnormality, tobacco use, HIV/immunosuppression, and obesity). Composite comorbidity was measured using the Charlson Comorbidity Index (CCI) $[36,37]$ with the Deyo modification [38]. This well-validated index contains 17 categories of comorbid conditions, derived from ICD-9 discharge codes, each assigned a weight from 1 to 6 (maximum score $=$ 33). ROSC and discharge disposition (home or long-term facility) were recorded. In patients with more than one arrest, each event was treated as separate and independent if separated by more than 24 hours (representing $2.7 \%$ of events).

2.4. Statistical Analysis. Statistical analysis was performed using GBStat v9.0 (Dynamic Microsystems) and Sigmastat v11.0 (Systat). Data were compiled as mean \pm SD. Testing for differences between means was done using Student's $t$-test for paired or unpaired variates or ANOVA as appropriate. Frequency data were tested using chi-square with continuity correction. Survival was defined as survival to discharge. To determine predictors of survival, demographic and patient characteristics were analyzed using univariate logistic regression. Those variables found to predict survival from CPA were then entered into a multivariate logistic regression model. The null hypothesis was tested at the two-tailed, 5\% level. Finally, association of age with comorbidities was analyzed with a Mann-Whitney test (for nonnormally distributed data) and with a Student's $t$-test for unpaired variables (cardiovascular disease was normally distributed).

\section{Results}

During the study period, 729 arrests occurred in 709 patients. Table 1 details patient demographics, admission service, and bed type for these patients. $476(67 \%)$ were male, with an average age of $58 \pm 16$ years. Caucasian and African Americans comprised 349 (51.8\%) and 290 (43\%) of patients, respectively. Most patients had a surgical or medical admitting service, with $122(16.7 \%)$ on cardiology. The majority of arrests, $453(62.1 \%)$, took place in an ICU.

Characteristics of arrest and the outcomes of resuscitation are shown in Table 2. The average duration of CPA was $24 \pm$ 22 minutes, and CPAs were evenly distributed throughout the day. 377 (50.8\%) CPAs were cardiac, 185 (24.9\%) were respiratory, and in $180(24.3 \%)$ the type of arrest could not be determined. Most arrests were witnessed 649 (91.4\%) and monitored (84.2\%). $383(53.9 \%)$ patients had a return of initial circulation following the resuscitation attempt, 150 (21.3\%) survived to discharge, and 70 (9.6\%) were discharged home.

Demographic and arrest variables which predicted survival are shown in Table 3. Surgical admission was associated with significantly greater survival (29\%) than medical (14\%) or cardiac (16\%) admission. ICU patients had significantly worse survival (14\%) compared with patients on monitored $(36 \%)$ or unmonitored (33\%) beds; there was no difference in survival between CPA on monitored or unmonitored floors. CPAs of respiratory etiology were associated with greater survival $(35 \%)$ versus those of cardiac (17\%) etiology. CPA 
TABLE 1: Patient characteristics: demographics, admission service, and level of monitoring.

\begin{tabular}{lcc}
\hline Gender & Male & 476 (67.1\%) \\
& Female & $233(32.9 \%)$ \\
\hline \multirow{2}{*}{ Age (years) } & & 1st quartile 18.4-47.4 \\
& $58 \pm 16$ & 2nd quartile 47.5-58.2 \\
& & 3rd quartile 58.3-69.8 \\
& & 4th quartile $>69.9$ \\
\hline \multirow{2}{*}{ Race } & Caucasian & $349(51.8 \%)$ \\
& African American & $290(43.0 \%)$ \\
& Asian & $25(3.7 \%)$ \\
Admission service & Other & $10(1.5 \%)$ \\
& Surgical & $312(42.8 \%)$ \\
& Medical & $264(36.2 \%)$ \\
& Cardiology & $122(16.7 \%)$ \\
Bed type & Unknown/other & $31(4.3 \%)$ \\
\hline & Intensive care unit & $453(62.1 \%)$ \\
& Floor & $144(19.8 \%)$ \\
& Telemetry & $118(16.2 \%)$ \\
& Unknown/other & $14(1.9 \%)$ \\
\hline
\end{tabular}

TABLE 2: Arrest characteristics.

\begin{tabular}{lcc}
\hline $\begin{array}{l}\text { Duration of CPA } \\
\left(\text { minutes) }{ }^{*} 574^{*}\right.\end{array}$ & $24.0 \pm 21.9$ & $\begin{array}{c}\text { 1st quartile: } 1-10 \\
\text { 2nd quartile: } 10.1-20 \\
\text { 3rd quartile: } 20.1-30 \\
\text { 4th quartile: }>30\end{array}$ \\
\hline Time of CPA & 12 a.m.-6 a.m. & $173(24.6 \%)$ \\
& 6 a.m.-12 p.m. & $172(24.5 \%)$ \\
& 12 p.m.-6 p.m. & $191(27.2 \%)$ \\
& 6 p.m.-12 a.m. & $165(23.5 \%)$ \\
\hline Etiology of CPA & Cardiac & $377(50.8 \%)$ \\
& Respiratory & $185(24.9 \%)$ \\
Witness & Unspecified & $180(24.3 \%)$ \\
\hline Monitor & Yes & $649(91.4 \%)$ \\
\hline Return of spontaneous & No & $61(8.6 \%)$ \\
Circulation (ROSC) & Yes & $612(84.2 \%)$ \\
\hline & No & $115(15.8 \%)$ \\
Discharge disposition & Other facilities & $383(53.9 \%)$ \\
& Home & $327(46.1 \%)$ \\
\hline
\end{tabular}

${ }^{*}$ Data available for 574 arrests.

duration predicted survival, with longer duration associated with decreased survival in a time-dependent fashion with $31 \%$ surviving to discharge if $<10$ minutes and $11 \%$ surviving to discharge if $>30$ minutes. Demographic and CPA characteristics
TABLE 3: (a) Variables predicting CPA survival. (b) Variables with no statistically significant impact on CPA survival.

(a)

\begin{tabular}{lccc}
\hline & Variable & $\begin{array}{c}\text { Survival } \\
(\%)\end{array}$ & $P$ value* \\
\hline Admission & Surgical & 29 & \\
service & Medical & 14 & 0.0002 \\
& Cardiac & 16 & \\
Bed status & ICU & 14 & \\
& Telemetry & 36 & $<0.0001$ \\
Etiology & Floor & 33 & \\
& Cardiac & 17 & $<0.0001$ \\
\multirow{4}{*}{ CPA duration } & Respiratory & 35 & \\
& 2nd quartile (10.1-20 min) & 25 & \multirow{2}{*}{0.002} \\
& 3rd quartile $(20.1-30 \mathrm{~min})$ & 13 & \\
& 4th quartile $(>30 \mathrm{~min})$ & 11 & \\
\hline
\end{tabular}

(b)

\begin{tabular}{lcc}
\hline & & Survival $(\%)^{*}$ \\
\hline \multirow{2}{*}{ Gender } & Male & 23 \\
& Female & 20 \\
\hline \multirow{3}{*}{ Age (quartiles) } & 1 st & 19 \\
& 2 nd & 23 \\
& 3rd & 24 \\
Race & 4th & 21 \\
\hline \multirow{2}{*}{ Witnessed } & Caucasian & 23 \\
& African American & 20 \\
\multirow{2}{*}{ Monitored } & Asian & 20 \\
\hline \multirow{2}{*}{ Time of arrest } & Yes & 25 \\
& No & 20 \\
\hline & Yes & 21 \\
& No & 23 \\
\hline
\end{tabular}

$$
{ }^{*} P=\mathrm{NS} \text {. }
$$

that did not predict survival were age, gender, race, presence of a witness, presence of a monitor, and time of day of CPA.

We assessed the influence of comorbidities on CPA outcome, using both a cumulative measure of chronic comorbidities (Charlson comorbidity index) and individual major system involvement. The Charlson index was not predictive of CPA survival (Table 4), with no significant difference in survival between patients in the lower or upper quartiles of scores.

In analysis of specific major system comorbidities (Table 5), 6 systems yielded significant effects on univariate analysis. We found, somewhat surprisingly, that neurologic diseases, trauma, and the presence of electrolyte disorders were associated with improved survival on multivariate analysis. Obesity significantly worsened survival, while the 
TABLE 4: Charlson scores and survival (by quartile).

\begin{tabular}{lc}
\hline Charlson score & Survival $(\%)^{*}$ \\
\hline $0-1$ & 22 \\
$1.1-2$ & 22 \\
$2.1-5$ & 22 \\
$5.1-12$ & 18 \\
\hline
\end{tabular}

${ }^{*} P=$ NS by chi square.

univariate negative effect of renal disease and HIV disappeared on multivariate analysis. The effect of age on comorbidities (Table 6) demonstrated a positive association of age with cardiovascular disease, pulmonary disease, diabetes, hypertension, and cancer. Negative associations with age were noted with trauma, infections, and HIV disease.

\section{Discussion}

The predictors of survival for inpatient CPA were surgical versus medical or cardiac admission service, non-ICU bed versus ICU bed, respiratory arrest versus cardiac arrest, and shorter CPA duration. Demographic characteristics such as age, gender, and race were not predictors of survival, although age was influential in incidence of comorbidities. Similarly, witnessed status, being on a monitored unit, and time of day of CPA did not predict survival. While comorbidity in aggregate by the Charlson index did not predict outcome, certain major system in-hospital comorbidities were predictors of survival, including neurologic disease, trauma, electrolyte abnormalities, and lack of obesity. Our overall patient demographics, rate of return of spontaneous circulation, and survival to discharge were similar to those of prior studies of in-hospital CPA [7, 9, 15, 16, 25].

The Charlson comorbidity index is the most extensively studied comorbidity index [39]. Its predictive validity for mortality has been demonstrated in various settings, including critical care settings [37,39-41]. It has been shown to have concurrent validity in comparisons with other indices of comorbidity and has favorable test-retest and interrater reliability [39]. We found that the Charlson index was not a predictor of either ROSC or survival to discharge, in concurrence with some published studies. For example, Taffet et al. found no association between the number of chronic conditions and CPA survival [23]. Müllner reported that premorbid conditions other than structural heart disease with poor functional status did not influence CPA outcomes [22].

However, several studies have found associations between specific comorbidities, such as azotemia or malignancy, and poor CPA survival $[23,24]$. We investigated whether a classification of comorbidities by major system involvement could define prognostic variables for CPA survival. We found that neurologic disease, trauma, and electrolyte abnormalities are associated with improved survival. It is likely that the positive association of these factors with CPA survival results from their amenability to specific treatments (i.e., respiratory support for neurologic conditions, surgical interventions in trauma, and electrolyte management). We also found that renal disease, HIV/immunosuppression, and obesity
TABLE 5: In-hospital organ system involvement and CPR survival.

\begin{tabular}{lccc}
\hline System & Deaths & $\begin{array}{c}\text { Univariate } \\
P \text { value }\end{array}$ & $\begin{array}{c}\text { Multivariate OR (CI), } P \\
\text { value }\end{array}$ \\
\hline $\begin{array}{l}\text { Neuro- } \\
\text { Neuro+ }\end{array}$ & $\begin{array}{c}393(81.2 \%) \\
\text { Renal- }\end{array}$ & 0.003 & $1.863(1.167-2.972), 0.009$ \\
Renal+ & $240(76.6 \%)$ & 0.019 & $0.981(0.639-1.506)$, NS \\
Trauma- & $410(80.4 \%)$ & 0.021 & $1.726(1.021-2.916), 0.041$ \\
Trauma+ & $65(69.1 \%)$ & & \\
Electrolyte- $366(82.1 \%)$ & 0.0009 & $2.058(1.326-3.193), 0.001$ \\
Electrolyte+ $109(69.0 \%)$ & & \\
HIV- & $435(77.8 \%)$ & 0.018 & $0.435(0.164-1.150)$ NS \\
HIV+ & $40(88.9 \%)$ & & \\
Obesity- & $392(76.9 \%)$ & 0.018 & $0.420(0.214-0.826), 0.012$ \\
Obesity+ & $83(88.3 \%)$ & & \\
-: organ system not involved. & & \\
+: organ system involved. & &
\end{tabular}

are associated with greater CPA mortality. Renal disease has previously been implicated in poor CPA outcome [24]. While obesity has been strongly associated with death from cardiovascular disease, its association with CPA mortality has not previously been shown [42]. In a multivariate logistic regression analysis, HIV/immunosuppression and renal disease were not predictors of CPA outcome, implying that the effects of these disorders are captured by including other systems.

Race, sex, and age were not significant predictors of CPA survival in our patient population. Review of the literature reveals significant disagreement regarding the influence of age on CPA survival. While some studies assert better survival for younger patients $[16,18,23]$, others have found no association between age and CPA outcomes $[6,13,28-30]$. Neither our data did indicate a significant contribution of age per se to CPA outcomes, nor did age significantly influence the comorbidities associated with poor outcomes at our institution. Our data argues against the consideration of age in clinical decision making regarding resuscitation.

Hospital setting has been extensively studied as a contributor to in-hospital resuscitation outcome. Our data indicated that time of day, presence of a witness, or telemetry monitoring is not significant predictors of CPA survival. Recently, an analysis of a large nationwide arrest database indicated lower survival rates for in-hospital cardiac arrest during nights and weekends [15]. Some of the factors which may have contributed to consistent arrest outcomes regardless of time of day at the University of Maryland include the availability of intensivists for assistance with management during and immediately after arrest, the use of designated "code teams" to respond to arrests hospital-wide, and the liberal allocation of nursing staff to code teams and postarrest ICU care. Our data suggest that individual hospitals may be able to eliminate the disparities in arrest outcomes based on time of day. A more thorough, hospital-by-hospital analysis of staffing and resource allocation practices that may improve night and weekend arrest outcomes is warranted. Additionally, 
TABLE 6: Morbidity by age.

\begin{tabular}{|c|c|c|c|c|c|}
\hline Organ system & $\begin{array}{c}\text { Test of } \\
\text { significance }\end{array}$ & $P$ & $\begin{array}{c}\text { Age for no } \\
\text { involvement }\end{array}$ & $\begin{array}{c}\text { Age for } \\
\text { involvement }\end{array}$ & Predictor of survival \\
\hline Neurologic & MW & NS & $58.9(21.8)$ & $63.2(24.7)$ & Yes \\
\hline Alcohol & MW & NS (0.058) & $59.4(22.7)$ & $53.9(17.8)$ & No \\
\hline Cardiovascular & $t$-test & 0.009 & $49.9(16.0)$ & $62.5(14.6)$ & No \\
\hline Pulmonary & MW & 0.017 & $57.2(21.1)$ & $62.2(24.2)$ & No \\
\hline Renal & MW & NS & $59.2(24.7)$ & $59.0(21.4)$ & Yes \\
\hline Endocrine & MW & NS & $47.1(22.4)$ & $48.6(21.7)$ & No \\
\hline GI & MW & NS & $46.7(22.8)$ & $47.6(21.7)$ & No \\
\hline $\mathrm{DM}$ & MW & $<0.001$ & $44.0(24.4)$ & $53.4(17.3)$ & No \\
\hline HTN & MW & $<0.001$ & $55.4(22.8)$ & $64.6(24.7)$ & No \\
\hline Trauma & MW & 0.001 & $59.7(20.6)$ & $51.1(36.0)$ & Yes \\
\hline Cancer & MW & $<0.001$ & $57.0(21.2)$ & $64.6(10.6)$ & No \\
\hline Infectious & MW & 0.003 & $62.3(20.4)$ & $55.9(11.0)$ & No \\
\hline Electrolytes & MW & NS & $59.1(22.6)$ & $60.1(22.3)$ & Yes \\
\hline Tobacco use & MW & NS & $59.2(22.2)$ & $58.7(24.0)$ & No \\
\hline HIV & MW & $<0.001$ & $45.6(21.5)$ & $59.0(12.1)$ & Yes \\
\hline Obesity & MW & NS & $59.2(23.4)$ & $60.0(17.4)$ & Yes \\
\hline
\end{tabular}

MW: Mann-Whitney test (nonnormally distributed data); $t$-test: Student's $t$-test for unpaired variates (normally distributed data). Data shown as for nonnormally distributed data: median (interquartile distance); for normally distributed data: mean (standard deviation). Predictors of survival are univariate predictors from Table 5 .

variation in intensity and quality of CPR and ACLS training might add to differences in outcomes of CPA at individual institutions.

We could not detect an effect of monitoring on outcomes in our analysis, likely due to a very high use of telemetry monitoring in our patient population, with $571(78.3 \%)$ of patients suffering arrests being in an ICU or telemetry setting. We found better outcomes for patients with a surgical rather than medical or cardiac admission service and worse survival to discharge for ICU versus monitored/unmonitored floor arrests. It is likely that the reduced survival among ICU arrest patients is due to more advanced and multisystem disease, as well as CPA despite an already increased level of monitoring and support in the ICU population.

The organ system primarily considered to be the cause of CPA serves as a predictor of survival in our study, with respiratory etiology having a more favorable outcome than cardiac etiology. This is consistent with prior studies suggesting that CPA with a primary respiratory etiology is more readily reversible $[9,25]$. We also found that shorter arrest duration is associated with survival as has been reported in prior studies $[16,18]$. Arrest duration likely reflects multiple factors such as extent of underlying disease, lag time between arrest and initiation of resuscitation efforts, and effectiveness of resuscitation itself. Prolonged arrest duration is also associated with poor end-organ perfusion, in part accounting for poor postarrest outcomes.

Trauma and surgical admissions suffering CPA demonstrated better outcomes than those in other settings. The reason for this is not clear from our analysis but certainly may relate to a more specific, recognized, and treatable set of complications that are found in trauma and surgical patients.

The major source of bias in any study of this type is the exclusion of patients in whom the decision was made to forgo resuscitation efforts. Characteristic patterns for these decisions will vary by country, specific patient population, and health-care provider culture, and while certainly influencing results in a study like this, they are very difficult to capture or quantify. One factor complicating the study of comorbidities in CPA survival is the possibility that the decision to attempt resuscitation may be influenced by comorbidities, excluding patients with more significant morbidity from inclusion in the dataset.

In summary, we examined the influence of patient demographic factors, comorbidities, organ system involvement, and arrest characteristics on survival to discharge in our large, urban, academic medical center with in house intensivist management of CPA and directing immediate postarrest care. Major predictors of survival for inpatient CPA identified in this study were admission service, CPA setting (ICU versus floor), primary etiology of arrest, and arrest duration. Age and other demographic factors did not predict survival. Furthermore, we found that the presence of a monitor, presence of a witness to the arrest, and time of day of arrest did not predict survival, suggesting that these factors are not critical to efficient response to CPA and effective resuscitation. Prehospital comorbidities as assessed by Charlson index did not predict survival, while specific major system comorbidities did predict outcomes. Our results suggest that while broad-based epidemiology of risk factors in CPA is useful, there are significant differences in these factors 
when applied to our specific institution. Therefore, hospitalsetting differences should be taken into account when making decisions regarding implementation of resuscitation efforts. Additionally, our particularly poor outcomes for CPA in ICU patients should merit an in-depth reevaluation of the benefit of offering resuscitation efforts to the majority of these patients.

\section{Disclosure}

All the authors had full access to all of the data in the study and take responsibility for the integrity of the data and the accuracy of the data analysis.

\section{Conflict of Interests}

The authors declare no conflict of interests with respect to the authorship and/or publication of this paper.

\section{References}

[1] W. B. Kouwenhoven, J. R. Jude, and G. G. Knickerbocker, "Closed-chest cardiac massage," The Journal of the American Medical Association, vol. 173, pp. 1064-1067, 1960.

[2] J. A. Cooper, J. D. Cooper, and J. M. Cooper, "Cardiopulmonary resuscitation: history, current practice, and future direction," Circulation, vol. 114, no. 25, pp. 2839-2849, 2006.

[3] P. S. Chan and B. K. Nallamothu, "Improving outcomes following in-hospital cardiac arrest: life after death," The Journal of the American Medical Association, vol. 307, no. 18, pp. 1917-1918, 2012.

[4] J. R. Jude, W. B. Kouwenhoven, and G. G. Knickerbocker, "Cardiac arrest. Report of application of external cardiac massage on 118 patients," The Journal of the American Medical Association, vol. 178, pp. 1063-1070, 1961.

[5] J. G. Lemire and A. L. Johnson, "Is cardiac resuscitation worthwhile? A decade of experience," The New England Journal of Medicine, vol. 286, no. 18, pp. 970-972, 1972.

[6] S. E. Bedell, T. L. Delbanco, E. F. Cook, and F. H. Epstein, "Survival after cardiopulmonary resuscitation in the hospital," The New England Journal of Medicine, vol. 309, no. 10, pp. 569-575, 1983.

[7] M. Rosenberg, C. Wang, S. Hoffman-Wilde, and D. Hickham, "Results of cardiopulmonary resuscitation: failure to predict survival in two community hospitals," Archives of Internal Medicine, vol. 153, no. 11, pp. 1370-1375, 1993.

[8] M. A. Peberdy, W. Kaye, J. P. Ornato et al., "Cardiopulmonary resuscitation of adults in the hospital: a report of 14720 cardiac arrests from the National Registry of Cardiopulmonary Resuscitation," Resuscitation, vol. 58, no. 3, pp. 297-308, 2003.

[9] M. Saklayen, H. Liss, and R. Markert, "In-hospital cardiopulmonary resuscitation: survival in 1 hospital and literature review," Medicine, vol. 74, no. 4, pp. 163-175, 1995.

[10] G. L. Larkin, W. S. Copes, B. H. Nathanson, and W. Kaye, "Preresuscitation factors associated with mortality in 49,130 cases of in-hospital cardiac arrest: a report from the National Registry for Cardiopulmonary Resuscitation," Resuscitation, vol. 81, no. 3, pp. 302-311, 2010.

[11] E. Kagawa, I. Inoue, T. Kawagoe et al., "Assessment of outcomes and differences between in- and out-of-hospital cardiac arrest patients treated with cardiopulmonary resuscitation using extracorporeal life support," Resuscitation, vol. 81, no. 8, pp. 968-973, 2010.

[12] J. Tian, D. A. Kaufman, S. Zarich et al., "Outcomes of critically ill patients who received cardiopulmonary resuscitation," American Journal of Respiratory and Critical Care Medicine, vol. 182, no. 4, pp. 501-506, 2010.

[13] P. G. Brindley, D. M. Markland, I. Mayers, and D. J. Kutsogiannis, "Predictors of survival following in-hospital adult cardiopulmonary resuscitation," CMAJ, vol. 167 , no. 4 , pp. $343-$ 348, 2002.

[14] M. M. Churpek, T. C. Yuen, M. T. Huber, S. Y. Park, J. B. Hall, and D. P. Edelson, "Predicting cardiac arrest on the wards: a nested case-control study," Chest, vol. 141, no. 5, pp. 1170-1176, 2012.

[15] M. A. Peberdy, J. P. Ornato, G. L. Larkin et al., "Survival from inhospital cardiac arrest during nights and weekends," The Journal of the American Medical Association, vol. 299, no. 7, pp. 785-792, 2008.

[16] S. Cooper, M. Janghorbani, and G. Cooper, "A decade of inhospital resuscitation: outcomes and prediction of survival?" Resuscitation, vol. 68, no. 2, pp. 231-237, 2006.

[17] M. A. Hajbaghery, G. Mousavi, and H. Akbari, "Factors influencing survival after in-hospital cardiopulmonary resuscitation," Resuscitation, vol. 66, no. 3, pp. 317-321, 2005.

[18] S. C. Schultz, D. C. Cullinane, M. D. Pasquale, C. Magnant, and S. R. T. Evans, "Predicting in-hospital mortality during cardiopulmonary resuscitation," Resuscitation, vol. 33, no. 1, pp. 13-17, 1996.

[19] J. Herlitz, S. Aune, A. Bång et al., "Very high survival among patients defibrillated at an early stage after in-hospital ventricular fibrillation on wards with and without monitoring facilities," Resuscitation, vol. 66, no. 2, pp. 159-166, 2005.

[20] R. De Vos, R. W. Koster, R. J. De Haan, H. Oosting, P. A. Van Der Wouw, and A. J. Lampe-Schoenmaeckers, "In-hospital cardiopulmonary resuscitation: prearrest morbidity and outcome," Archives of Internal Medicine, vol. 159, no. 8, pp. 845-850, 1999.

[21] G. Treanor, K. Spearpoint, and S. Brett, "Survival from inhospital cardiac arrest: the potential impact of infection," Resuscitation, vol. 64, no. 1, pp. 59-62, 2005.

[22] M. Müllner, "The influence of chronic prearrest health conditions on mortality and functional neurological recovery in cardiac arrest survivors," American Journal of Medicine, vol. 104, no. 4, pp. 369-373, 1998.

[23] G. E. Taffet, T. A. Teasdale, and R. J. Luchi, "In-hospital cardiopulmonary resuscitation," Journal of the American Medical Association, vol. 260, no. 14, pp. 2069-2072, 1988.

[24] A. L. George Jr., B. P. Folk III, P. L. Crecelius, and W. B. Campbell, "Pre-arrest morbidity and other correlates of survival after in-hospital cardiopulmonary arrest," American Journal of Medicine, vol. 87, no. 1, pp. 28-34, 1989.

[25] S. C. Danciu, L. Klein, M. M. Hosseini, L. Ibrahim, B. W. Coyle, and R. F. Kehoe, "A predictive model for survival after inhospital cardiopulmonary arrest," Resuscitation, vol. 62, no. 1, pp. 35-42, 2004.

[26] P. A. Meaney, V. M. Nadkarni, K. B. Kern, J. H. Indik, H. R. Halperin, and R. A. Berg, "Rhythms and outcomes of adult inhospital cardiac arrest," Critical Care Medicine, vol. 38, no. 1, pp. 101-108, 2010.

[27] P. S. Chan, G. Nichol, H. M. Krumholz et al., "Racial differences in survival after in-hospital cardiac arrest," The Journal of the American Medical Association, vol. 302, no. 11, pp. 1195-1201, 2009. 
[28] D. Tresch, G. Heudebert, K. Kutty, J. Ohlert, K. VanBeek, and A. Masi, "Cardiopulmonary resuscitation in elderly patients hospitalized in the 1990s: a favorable outcome," Journal of the American Geriatrics Society, vol. 42, no. 2, pp. 137-141, 1994.

[29] C. Brymer, E. Gangbar, K. O’Rourke, and G. Naglie, “Age as a determinant of cardiopulmonary resuscitation outcome in the coronary care unit," Journal of the American Geriatrics Society, vol. 43, no. 6, pp. 634-637, 1995.

[30] J. Varon and R. E. Fromm Jr., "In-hospital resuscitation among the elderly: substantial survival to hospital discharge," American Journal of Emergency Medicine, vol. 14, no. 2, pp. 130-132, 1996.

[31] R. Jain, B. K. Nallamothu, and P. S. Chan, "Body mass index and survival after in-hospital cardiac arrest," Circulation, vol. 3, no. 5, pp. 490-497, 2010.

[32] P. S. Chan, H. M. Krumholz, J. A. Spertus et al., "Automated external defibrillators and survival after in-hospital cardiac arrest," The Journal of the American Medical Association, vol. 304, no. 19, pp. 2129-2136, 2010.

[33] P. S. Chan, R. Jain, B. K. Nallmothu, R. A. Berg, and C. Sasson, "Rapid response teams: a systematic review and meta-analysis," Archives of Internal Medicine, vol. 170, no. 1, pp. 18-26, 2010.

[34] G. Nichol, P. Steen, J. Herlitz et al., "International Resuscitation Network Registry: design, rationale and preliminary results," Resuscitation, vol. 65, no. 3, pp. 265-277, 2005.

[35] "Guidelines 2000 for Cardiopulmonary Resuscitation and Emergency Cardiovascular Care. Part 6: advanced cardiovascular life support: 7C: a guide to the International ACLS algorithms. The American Heart Association in collaboration with the International Liaison Committee on Resuscitation," Circulation, vol. 102, supplement 8, pp. I142-I157, 2000.

[36] M. E. Charlson, P. Pompei, K. A. Ales, and C. R. MacKenzie, "A new method of classifying prognostic comorbidity in longitudinal studies: development and validation," Journal of Chronic Diseases, vol. 40, no. 5, pp. 373-383, 1987.

[37] M. Charlson, T. P. Szatrowski, J. Peterson, and J. Gold, "Validation of a combined comorbidity index," Journal of Clinical Epidemiology, vol. 47, no. 11, pp. 1245-1251, 1994.

[38] R. A. Deyo, D. C. Cherkin, and M. A. Ciol, "Adapting a clinical comorbidity index for use with ICD-9-CM administrative databases," Journal of Clinical Epidemiology, vol. 45, no. 6, pp. 613-619, 1992.

[39] V. De Groot, H. Beckerman, G. J. Lankhorst, and L. M. Bouter, "How to measure comorbidity: a critical review of available methods," Journal of Clinical Epidemiology, vol. 56, no. 3, pp. 221-229, 2003.

[40] R. M. Poses, D. K. McClish, W. R. Smith, C. Bekes, and W. E. Scott, "Prediction of survival of critically ill patients by admission comorbidity," Journal of Clinical Epidemiology, vol. 49, no. 7, pp. 743-747, 1996.

[41] D. M. Needham, D. C. Scales, A. Laupacis, and P. J. Pronovost, "A systematic review of the Charlson comorbidity index using Canadian administrative databases: a perspective on risk adjustment in critical care research," Journal of Critical Care, vol. 20, no. 1, pp. 12-19, 2005.

[42] E. E. Calle, M. J. Thun, J. M. Petrelli, C. Rodriguez, and C. W. Heath Jr., "Body-mass index and mortality in a prospective cohort of U.S. adults," The New England Journal of Medicine, vol. 341, no. 15, pp. 1097-1105, 1999. 


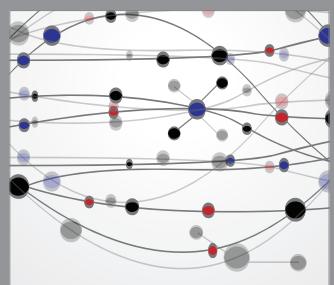

The Scientific World Journal
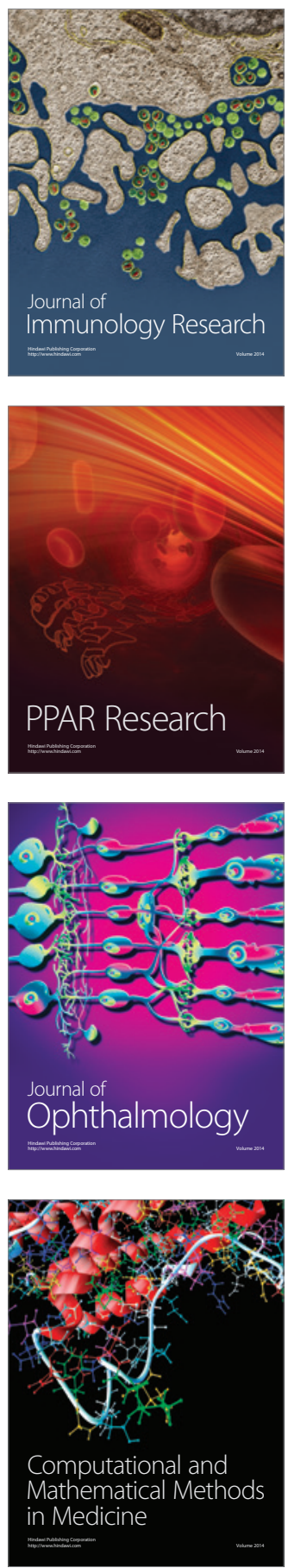

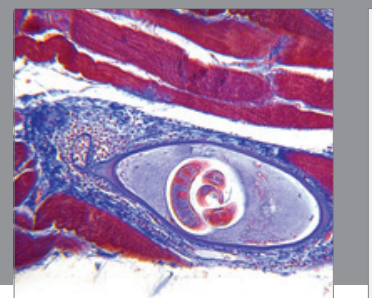

Gastroenterology

Research and Practice
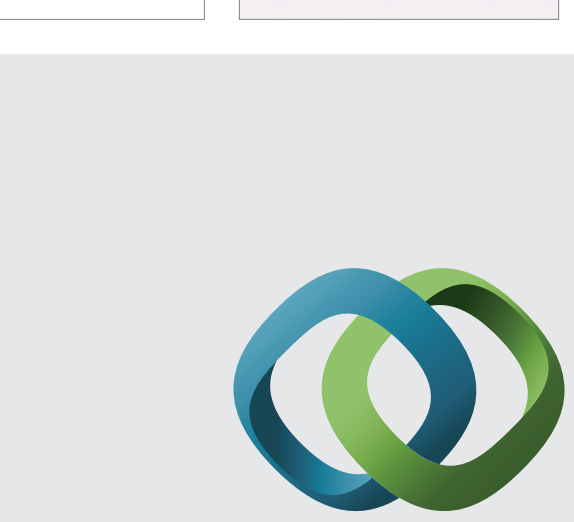

\section{Hindawi}

Submit your manuscripts at

http://www.hindawi.com
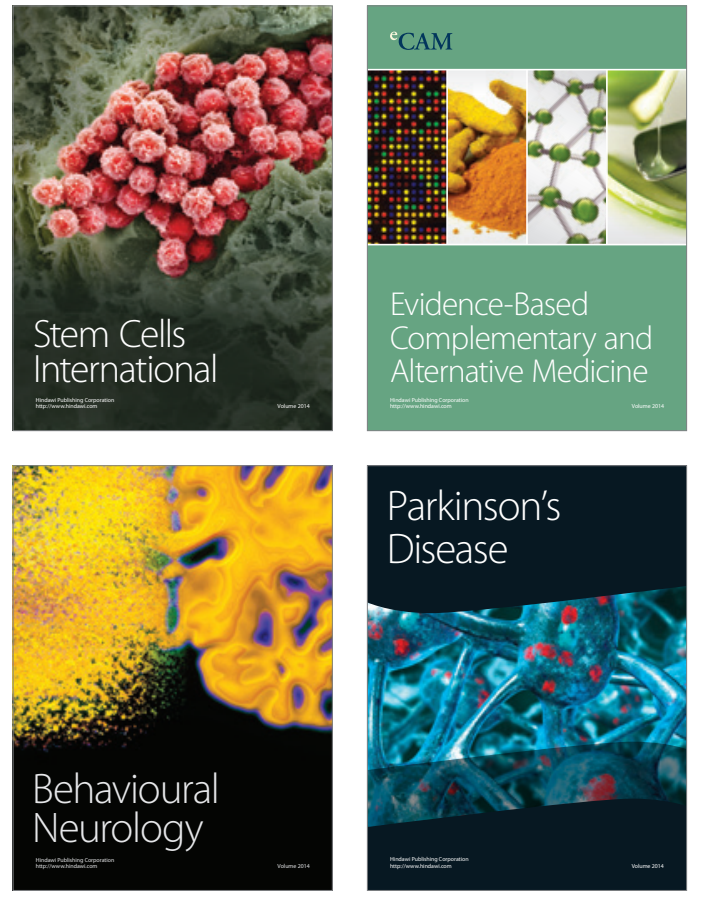
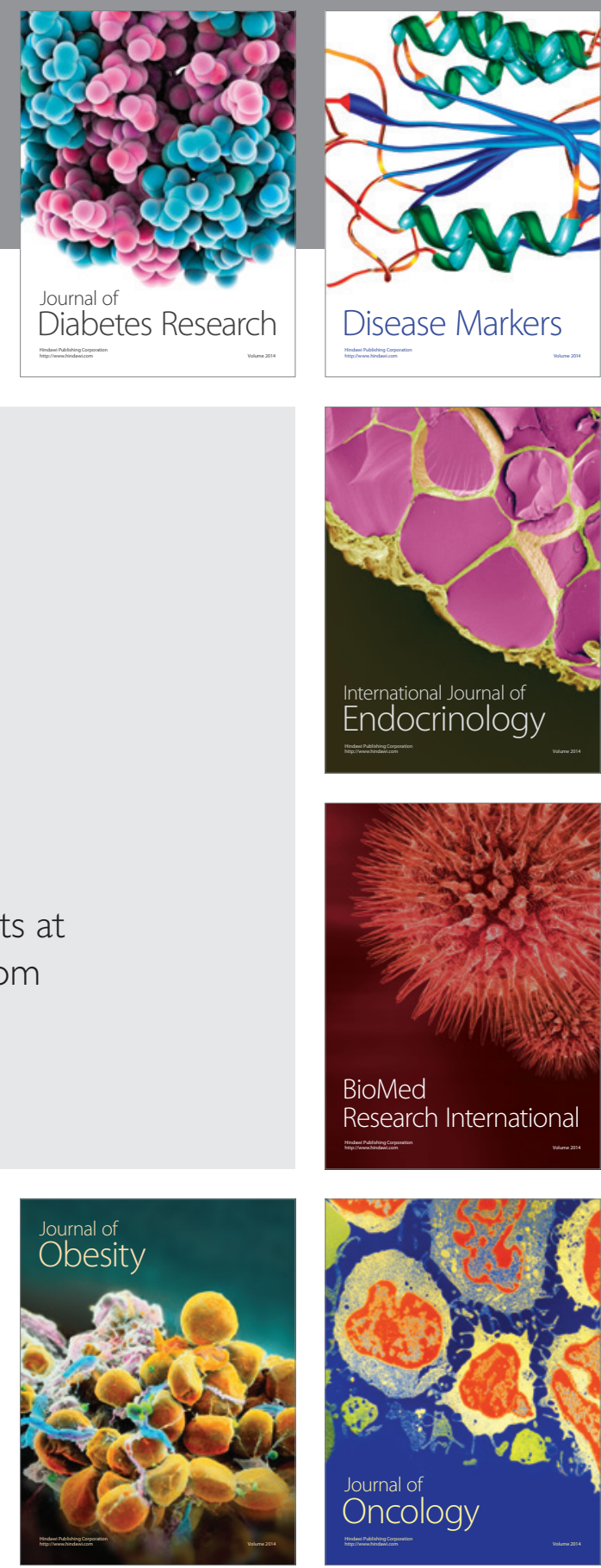

Disease Markers
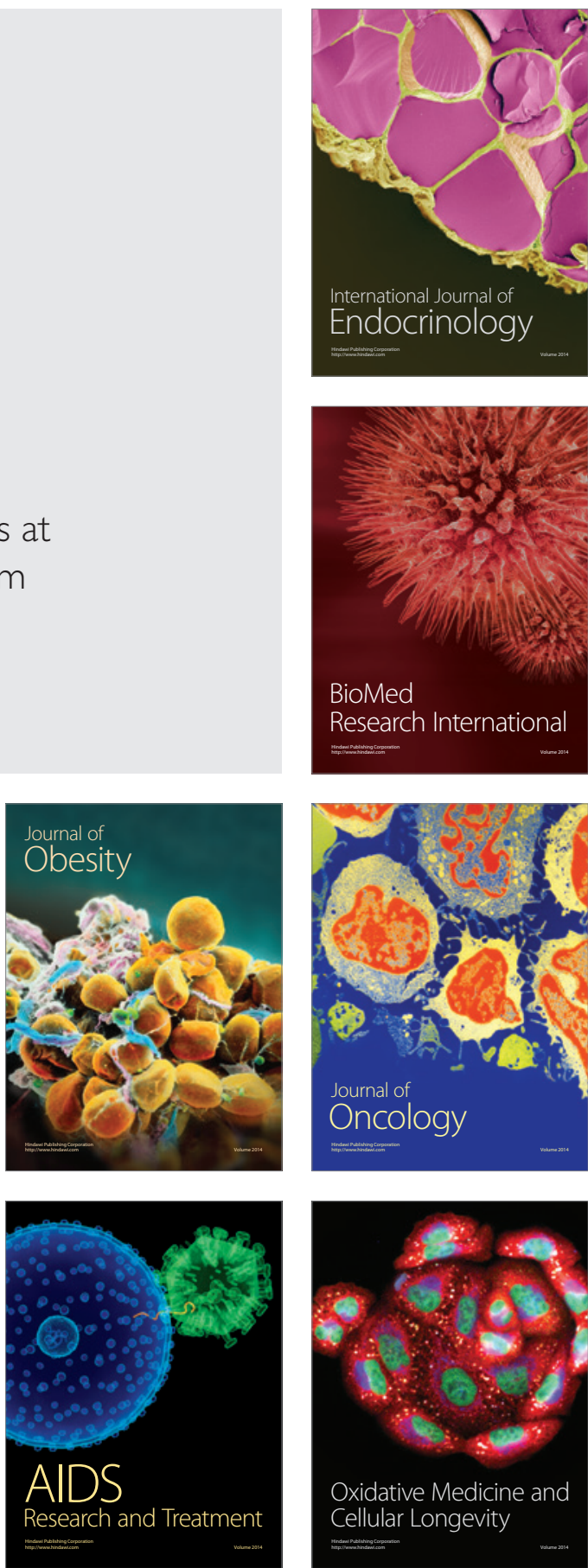